\title{
Idiopathic bilateral masseter muscle hypertrophy in adolescent females of same family treated conservatively: a rare case report
}

\author{
Karnawat BS ${ }^{1}$, Saraswat $D^{2}$ \\ Dr B S Karnawat, Senior Professor \& Head of Department Pediatrics, JLN Medical College, Ajmer. Dr Devina Saraswat, \\ Resident Pediatrics, JLN, Ajmer, Rajasthan, India
}

Address of correspondence: devina060788@gmail.com Dr Devina Saraswat

\begin{abstract}
Idiopathic hypertrophy of the masseter muscle is a rare disorder of unknown cause. Most patients complain of the cosmetic change caused by facial asymmetry, also called as Square face, however symptoms such as trismus, protrusion,bruxism may also occur. The goals of the present article are to- report 2 cases of idiopathic masseter hypertrophy within a same family, describe its symptoms and treatment. The main presenting complaints were bilateral bulging in the region of angle of mandible, of slow and progressive evolution and managed conservatively as oppose to the routine surgical treatment used so far.
\end{abstract}

Keywords: Idiopathic Masseter Muscle Hypertrophy, Conservative Management, Anxiety, Adolescent Female

\section{Introduction}

Idiopathic masseter muscle hypertrophy (IMMH) was first described by Legg in 1880, reporting the case of a 10 year old girl with concurrent idiopathic temporalis muscle hypertrophy[ $1,2,3,4,7]$. The masseter muscle is essential for mastication and is located laterally to the mandibular ramus, and thus plays an important role in facial lines, generating discomfort and negative cosmetic impacts for many patients [1,2] . Muscle function may also be impaired thus introducing conditions such as trismus, protrusion[2,3].

The aetiology of this condition remains obscure[ 1-6], but some authors have correlated it to gum chewing, psychological disorders and temporomandibular joint disorders. It can affect anyone, regardless of age, gender, and ethnicity $[1,2,3,6]$, and also involves both side of face [1-6]. Differential diagnosis requires clinical history and physical examination and even CT Scans to exclude other lesions [1-5]. Differential diagnosis must include muscle tumours, salivary gland diseases, parotid tumours, parotid inflammatory diseases and intrinsic masseter muscle myopathy [ 1,24]. Treatment used till now is surgical ( intraoral or extraoral approaches).

Manuscript received: $09^{\text {th }}$ Dec 2015

Reviewed: $20^{\text {th }}$ Dec 2015

Author Corrected: $01^{\text {st } J a n ~} 2016$

Accepted for Publication: $10^{\text {th }}$ Jan 2016
This article describes two case of IMMH in same family and even proposes an effective treatment option.

\section{Case Report}

Case1- Oshin 14 year Muslim female child presented to our children OPD ( Department of Paediatrics) with complaint of bilateral increasing swelling over both mandibles.

The swelling was insidious in onset left $>$ right mandibular region, appeared simultaneously on both sides and was painless.

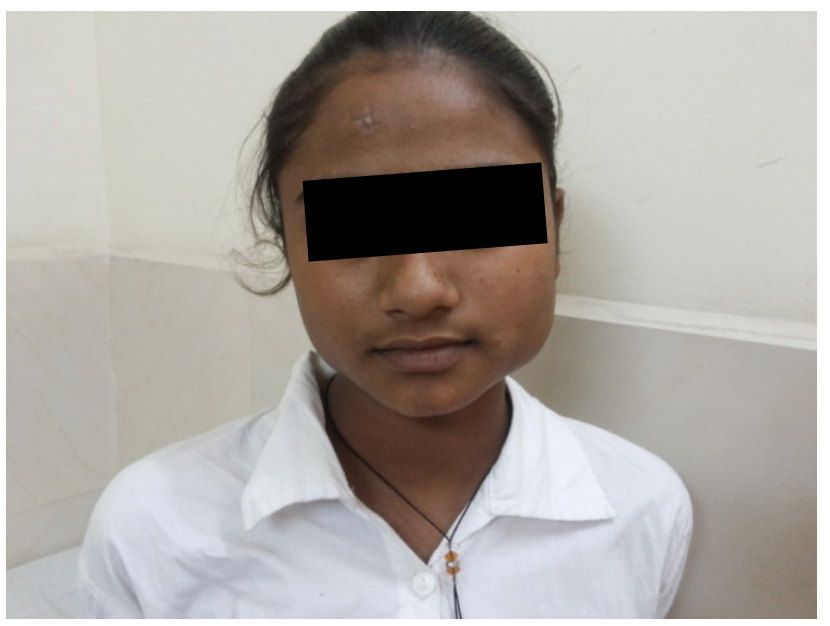



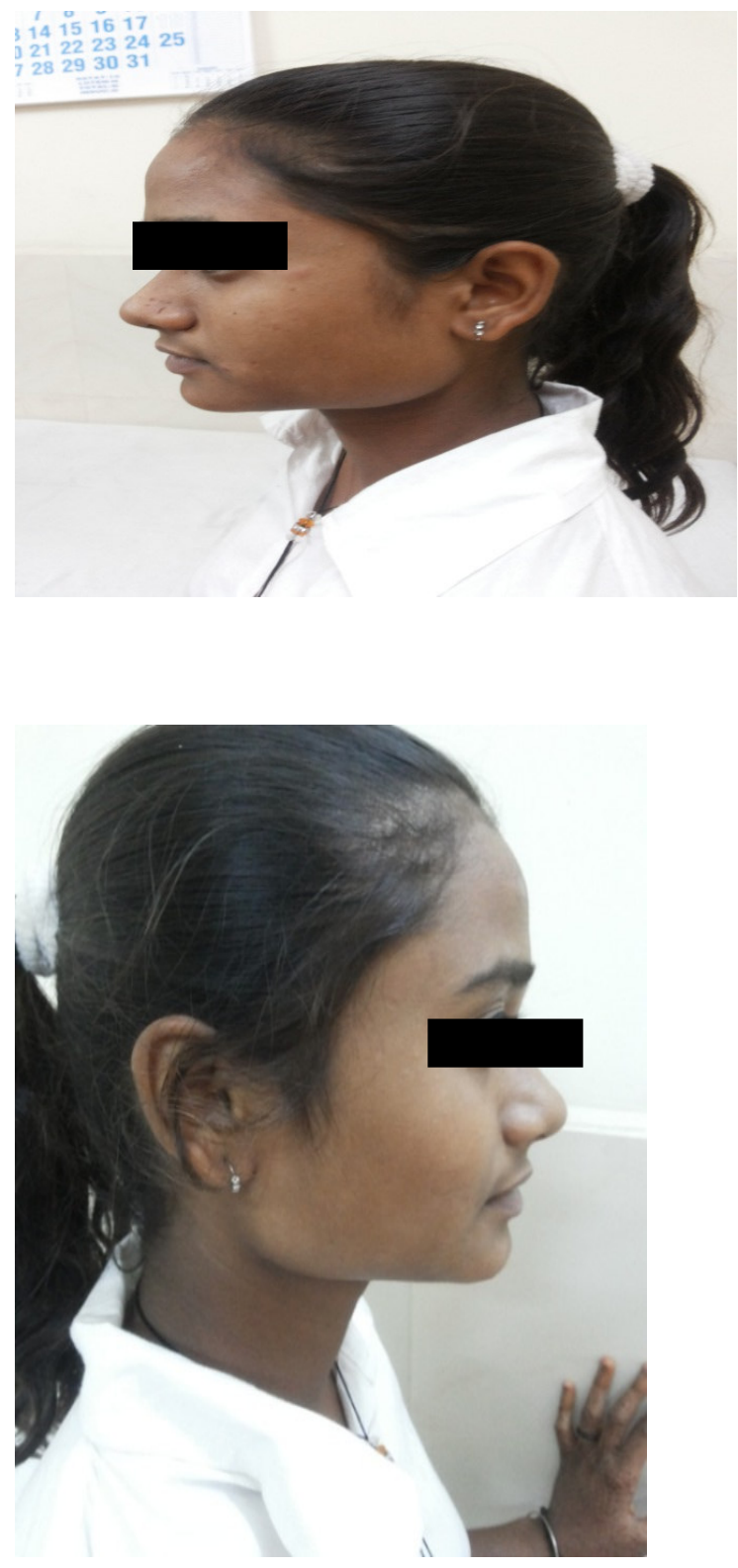

Examination of oral cavity showed no dental caries, good oral hygiene, no ma-locclusion, there were no signs of local inflammation. No limitation on opening of mouth. On palpation it was non tender.

Routine blood investigations were ordered including CBC, ESR, LDH, SGPT, SERUM AMYLASE, USG of local region. \& X-ray TMJ.

CASE 2- 7 days later, Noor 10 year Muslim female child presented to the OPD with similar complaints of gradually increasing swelling over both mandibles. There was no history of fever or trauma, but she reported it to be painful.
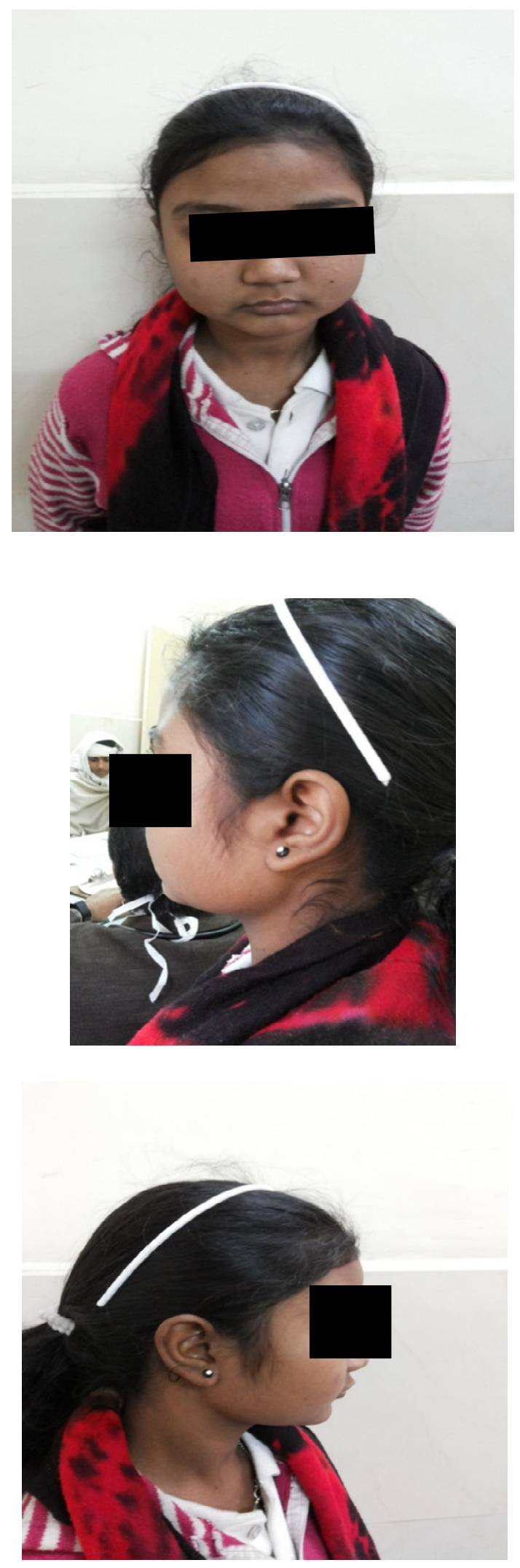
Examination of oral cavity showed no signs of local inflammation, or enlargement of salivary glands, nontender swelling, no limitation in opening mouth. Routine blood investigations along with USG wereadvised.

CBC of case 1 were as follows ; TLC- 4500 cumm, DLC- L-20\%, N- 76\%, Platelet- 3,20,000, ESR- 18, CRP- non Reactive, SGPT- 45, LDH- 30, X-ray temporomandibular region was normal

USG of local swelling suggested of bilateral enlargement of the underlying muscle in the region, parotid and submandibular glands were normal.

Case 2 routine investigations were- TLC $-5670 \mathrm{cumm}$, DLC- L-36\%, N- 66\%, platelet-2,50,890. ESR- 22, Xray TM joint normal, USG suggested similar finding of muscle hypertrophy.

Therefore no further investigations were done as likely possibility of infectious pathology or tumour of local region wasdisproved. Family history was positive both were sisters, Belonged to joint family, stress was found to be a common factor in both, as per there living conditions. Therefore it was considered to be a case of Idiopathic Masseter Muscle Hypertrophy, with anxiety and stress as a precipitating cause.

\section{Discussion}

IMMH is a rare condition, but an increasing number of cases and use of surgical techniques in its treatment have been described in literature. The causes of IMMH require further clarification, but certain conditions seem to be associated with masseter muscle hypertrophy such as psychological disorders, gum chewing and dysfunction of temporomandibular joint. Very few studies have reported that anxiety is often present in IMMH patients. The trismus experienced is related to stress and anxietyepisodes. Cosmetic alterations are the main complaints of IMMH. Paper describes stress and anxiety as two important causes of masseter hypertrophy.IMMH diagnosis is eminently clinical and is based on identification of symptoms and cosmetic facial alterations due to progress of disease.Physical examination and palpation reveals inflammation free muscle to support the diagnosis. We should always consider in differential diagnosis tumours in the large salivary glands (parotid, sub-mandibular), bony tumours of face, muscle and salivary glands inflammatory process. CT \& MRI is done in case of doubt about masseter muscle conditions (Seltzer \& Wang, 1987) [9]. According to Maxwell \& Weggoner (1951)neurologic tests and electro-myography is not required.[10].

We took family history and personal history and realised about the psychological stress of the girls, did counselling along with an anxiolytic tab alprazolam $2.5 \mathrm{mg}$ half tablet H.S for 7 days, along with tab multivitamin, tab calcium and reassurance.

On follow up about 2 weeks later swelling had started subsiding, they had a better moral boost up, and much more confident.

\section{Conclusion}

IMMH is a disease of obscure aetiology that may involve anybody. Although the diagnosis is eminently clinical, complementary examinations may aid in differential diagnosis against other conditions. The chosen conservative treatment mainly depends upon underlying aetiology. On contrary surgical treatment rely heavily on surgeon experience and skill, if at all surgery is required.

\section{References}

1. Cruz RL, Nunes MM, Radwanski HN. Idiopathic Hypertrophy of masseter; therapeutics and review of literature. Rev Bras Cir 1994;84(1):35-43

2. Teixeira VC, Mejja JES, Estefano A treatment options of benign hypertrophy of masseter muscle . Rev Bras Cir 1996;86(4); 165-70

3. Soares MM, Salgado CV, Pitta MC, Jorge WA. Hipertrofia benigna do musculo masseter. Rev ABO Nac 1994;2(3): 200-2.

4. Black MJ, Schloss MD . Massetric muscle hypertrophy. JOtolaryngol 1985; 14 (3) :203-5

5. Fyfe EC, Kabala J, Guest PG.Magnetic resonance imaging in the diagnosis of asymmetrical bilateral mesenteric hypertrophy. Dentomaxillofac Radiol 1999; 28: $52-4$

6. Jimenez LF. Difficult intubation in a patient with benign masseteric muscle hypertrophy. British J Anaesthesia; 2001

7. Legg W. enlargement of the temporal and masseter muscle in both sides. Jr Path Soc London. 1880:63 (5):361-4. 
8. Whitaker LA. Prominent mandibular angle : preoperative management, operative techniques and results in 42 patients( discussion). Plast Reconst Surg 1989:83:279

9. Seltzer SE, Wang AM Modern imaging of the masseter muscle : normal anatomy and pathosis on CT and MRI. Oral Surg. Oral Med. Oral pathol 1987: 63 (5):622-9
10. Maxwell JH, Weggoner RN. Hypertrophy of the masseter muscles. Ann otol 1951:60:538-41.

11. Gurney CE, Chronic bilateral benign hypertrophy of the masseter muscle, Ann J Surg 1947:73:137-9.

12. Daniel ZR, Paulo MC, Jose L, Pieres JR, Vinicius RF, Mandelli KK, Pereira MA . Benign masseter muscle hypertrophy. Rev Bras Otorhinolaryngol 2008;74(5):790-793

\section{How to cite this article?}

Karnawat BS, Saraswat D. Idiopathic bilateral masseter muscle hypertrophy in adolescent females of same family treated conservatively: a rare case report. Pediatr Rev: Int J Pediatr Res 2016;3(1):69-72.doi:10.17511/ijpr.2016.i01.13 